\title{
Prion protein is essential for the RE1 silencing transcription factor (REST)- dependent developmental switch in synaptic NMDA receptors
}

\author{
Zhiqi Song ${ }^{1,2}$, Wei Yang ${ }^{1,3}$, Guangyu Cheng ${ }^{1}$, Xiangmei Zhou' ${ }^{1}$ Lifeng Yang ${ }^{1}$ and Deming Zhao ${ }^{1}$
}

\begin{abstract}
It is important that the correct amounts of GluN2 subunits are maintained, as they determine NMDAR functional properties, which are crucial to neuronal communication, synaptogenesis and cognitive function. The transcriptional repressor RE1 silencing transcription factor (REST) is critical for the postnatal developmental switch in NMDARs. However, the mechanisms triggering REST and the link between NMDARs and REST are unclear. Here we show a new physiological essential role for cellular prion protein $\left(\operatorname{PrP}^{C}\right)$ in REST-dependent homeostasis and the developmental switch of NMDARs. REST and REST-associated proteins were overactivated in the hippocampi of Prnp knockout mice $\left(P r n p^{0 / 0}\right)$ compared with wild-type Prnp $\left(\operatorname{Prnp}^{+/+}\right)$mice. This coincided with the disruption of the normal developmental switch from GluN2B-to-GluN2A in vivo. PrPC co-located with REST under physiological environments and mediated the translocation of REST in conditioners of NMDARs in vitro in Prnp ${ }^{+/+}$hippocampal neurons. Regardless of whether REST was knocked down or overexpressed, deletion of $\operatorname{PrP}^{C}$ not only disrupted REST-mediated distribution of mitochondria, but also prevented REST-regulated expression of GluN2B and GluN2A in Prnp ${ }^{0 / 0}$.

Importantly, these effects were rescued after overexpression of full-length $\operatorname{PrP}^{C}$ through restoration of NMDAR2 subunits and their distributions in dendritic processes in $\operatorname{Prnp}{ }^{0 / 0}$. Consistently, knockdown of $\operatorname{PrPC}^{\mathrm{C}}$ in $\operatorname{Prnp}^{+/+}$ had a similar effect on Prnp ${ }^{0 / 0}$. Furthermore, $\operatorname{PrP}^{C}$ colocalized with both GluN2B and GluN2A in Prnp ${ }^{+/+}$. For the first time, we demonstrate that $\operatorname{PrP}^{C}$ is essential for REST-regulated NMDARs. Confirming the regulation of NMDARmodulating mechanisms could provide novel therapeutic targets against dysfunctions of glutamatergic transmission in the nervous system.
\end{abstract}

\section{Introduction}

$N$-methyl-D-aspartate receptors (NMDARs) are glutamate-gated ion channels critical for synaptogenesis

\footnotetext{
Correspondence: Deming Zhao (zhaodm@cau.edu.cn)

${ }^{1}$ The State Key Laboratories for Agrobiotechnology, Key Lab of Animal Epidemiology and Zoonosis, Ministry of Agriculture, National Animal

Transmissible Spongiform Encephalopathy Laboratory, College of Veterinary

Medicine, China Agricultural University, 100193 Beijing, China

${ }^{2}$ Institute of Laboratory Animal Sciences, Chinese Academy of Medical

Sciences (CAMS) and Comparative Medicine Center, Peking Union Medical

Collage (PUMC), Key Laboratory of Human Disease Comparative Medicine,

Ministry of Health, 100021 Beijing, China

Full list of author information is available at the end of the article.

Edited by A. Verkhrtasky
}

and neuronal communication ${ }^{1}$. These heterotetrameric channels are formed by the assembly of two obligatory GluN1 and two GluN2/GluN3 subunits ${ }^{2,3}$. NMDARs subunit composition is plastic and diverse, leading to abundant receptor subtypes, each with its own biophysical and pharmacological properties ${ }^{1}$. The subunit isoform of NR2 (GluN2) is a key determinant of the functional capabilities of NMDARs, including activation, deactivation and desensitization kinetics ${ }^{4}$. A developmental switch from containing primarily GluN2B-to-GluN2A occurs during postnatal development in NMDARs ${ }^{5}$. This switch, as well as the correct GluN2A/CluN2B ratio, is critical for

\section{(c) The Author(s) 2018}

(c) (i) Open Access This article is licensed under a Creative Commons Attribution 4.0 International License, which permits use, sharing, adaptation, distribution and reproduction cc) in any medium or format, as long as you give appropriate credit to the original author(s) and the source, provide a link to the Creative Commons license, and indicate if changes were made. The images or other third party material in this article are included in the article's Creative Commons license, unless indicated otherwise in a credit line to the material. If material is not included in the article's Creative Commons license and your intended use is not permitted by statutory regulation or exceeds the permitted use, you will need to obtain permission directly from the copyright holder. To view a copy of this license, visit http://creativecommons.org/licenses/by/4.0/. 
neural circuitry $^{6}$, hippocampus-dependent learning ${ }^{7}$, plasticity-induced alpha-amino-3-hydroxy-5-methyl-4isoxazolepropionic acid (AMPA) receptors ${ }^{8}$ and spine growth $^{9}$. A previous report has shown that the transcriptional repressor element 1-silencing transcription factor (REST), also known as neuron-restrictive silencer factor $^{10}$, participates in the postnatal switch in synaptic NMDAR subunit by decreasing GluN2B expression through epigenetic remodeling of Grin $2 b$ at rat hippocampal synapses. During postnatal development, REST shows both target and temporal characteristics in differentiated neurons for GluN2B ${ }^{11}$. REST acts as a multiple hub in coordination with other factors regulating the multiple aspects of neurogenesis and preserving the distinct neural phenotype ${ }^{10}$. However, as a switch from primarily GluN2B-to-GluN2A, the mechanisms that trigger REST expression in differentiated neurons, and the following long-term increase in GluN2A expression during postnatal development, are still unclear.

Although under normal conditions NMDA receptors mediate important physiological functions such as learning and memory, they also take part in glutamate excitotoxicity, which can occur in response to ischemia and is related to many neurodegenerative diseases, including Alzheimer's Disease (AD) ${ }^{12}$. Hence, strict regulation of NMDAR activity plays a key role in homeostasis by preventing excitotoxicity ${ }^{13}$. It is well established that misfolded forms of cellular prion protein $\left(\mathrm{PrP}^{\mathrm{C}}\right)$ transform into the $\beta$-sheet-rich, aggregate-prone scrapie conformation $\left(\operatorname{PrP}^{\mathrm{Sc}}\right)$, resulting in several progressive fatal diseases, known as prion diseases. These transmissible spongiform encephalopathies include bovine spongiform encephalopathy, scrapie, Creutzfeld-Jakob disease, GerstmannStraussler-Scheinker syndrome in humans ${ }^{14,15}$. Although research has been conducted exploring the harmful effects of misfolded or aggregated prion proteins, the physiological roles of $\operatorname{PrP}^{C}$ remain only partly understood.

Recent studies have demonstrated that $\operatorname{PrP}^{\mathrm{C}}$ also communicates with NMDARs; $\operatorname{PrP}^{\mathrm{C}}$-deficient mice exhibit enhanced NMDAR-dependent neuronal excitability and are more susceptible to NMDA-induced excitotoxicity ${ }^{16}$. Research has cumulatively demonstrated that the absence of $\operatorname{PrP}^{\mathrm{C}}$ increased NMDAR glycine affinity, resulting in persistent NMDAR activity after prolonged agonist treatment ${ }^{17} \cdot \operatorname{PrP}^{\mathrm{C}}$ and GluN2D are found in the same protein complex and colocalize in hippocampal neurons ${ }^{16}$. However, in the absence of $\operatorname{PrP}^{\mathrm{C}}$, it is still not clear whether other subunits of NMDARs are altered. Therefore, more details of $\mathrm{PrP}^{\mathrm{C}}$-mediated regulation of NMDARs need to be revealed.

Here, we explore the relationship between $\operatorname{PrP}^{\mathrm{C}}$ and REST-dependent developmental switch from GluN2B-toGluN2A. Our data show that a lack of $\operatorname{PrP}^{\mathrm{C}}$ gives rise to REST overexpression and disorder of REST-associated proteins in the hippocampus of neonatal mice. REST- dependent epigenetic remodeling of the developmental switch of NMDARs is also suppressed in vivo. Comparing wild-type (WT; Prnp ${ }^{+/+}$) and Prnp knockout $\left(\right.$Prnp $^{0 / 0}$ ) mice primary cultured hippocampal neurons, we found that $\operatorname{PrP}^{C}$ not only affects the translocation of REST, but also partially mediates REST-regulated mitochondria distribution and the developmental switch in synaptic NMDARs. The adverse effects induced by overactivated REST in $\operatorname{Prnp}^{O / O}$ neurons are recapitulated by overexpression of exogenous $\operatorname{PrP}^{\mathrm{C}}$. Thus, we demonstrate a novel functional role for native $\operatorname{PrP}^{\mathrm{C}}$ as an essential modulator of REST-dependent NMDARs activity, and provide more evidence to support the hypothesis that $\mathrm{PrP}^{\mathrm{C}}$ is a regulator of NMDARs.

\section{Results}

Overexpression of REST and alterations of REST-associated proteins in the hippocampi of postnatal $\operatorname{Prnp}^{0 / 0}$ mice

In almost all tissues, including the brain, epigenetic modification of chromatin is an important modulator of gene expression ${ }^{18,19}$. First, we confirmed the developmental expression of $\mathrm{PrP}^{\mathrm{C}}$ in the hippocampus of $\mathrm{Prnp}^{+/+}$ neonatal mice. Consistent with previous reports ${ }^{20,21}, \mathrm{PrP}^{\mathrm{C}}$ levels increased during the first two postnatal weeks, reached a peak at P13 and were slightly diminished in the adult (Fig. 1a, b). Second, we tested and compared postnatal expression of REST, postsynaptic density $95 \mathrm{kDa}$ protein (PSD-95), synaptophysin (SYP), GluN2B, GluN2A and NMDAR1 in the hippocampal homogenates of Prnp $^{+/+}$and Prnp ${ }^{0 / 0}$ neonatal mice.

In the WT group, contrary to the tendency of $\operatorname{PrP}^{\mathrm{C}}$, a transient, but marked increase in REST abundance occurred at postnatal day 3 (P3; Fig. 1a, b), with a subsequent, and constant, abundance of GluN2B protein from P7 until P13. REST abundance then declined $~ 2.25$ fold (relative to P3) to a level that persisted until adulthood (Fig. 1e, f). GluN2A protein was barely detectable at P3, and its levels progressively increased $\sim 6.43$-fold by $\mathrm{P} 30$ relative to that at $\mathrm{P} 3$, and continued to increase until P60 (nearly ninefold) (Fig. 1e, g). NMDAR1 levels gradually increased in a similar way to GluN2A (Fig. 1e, h).

In the Prnp ${ }^{O / O}$ group, REST expression significantly increased after P5 ( 9.32-fold) and the highest levels were seen at P13 ( 28.32-fold) relative to P3 (Fig. 1c, d). Although GluN2B levels progressively declined after P3 (Fig. 1i, j), GluN2B showed higher expression from P3 to P30 compared with the WT group (Fig. 2a, d). GluN2A was barely detectable before P5, but its expression markedly increased from P7 to P13 (Fig. 1i, k). NMDAR1 was strongly expressed from P3 to P7 and decreased to undetectable levels at P60 (Fig. 1i, l).

Compared with WT controls, Prnp ${ }^{0 / 0}$ mice showed significantly higher expression of REST (Fig. 2c), GluN2B (Fig. 2d) and GluN2A (Fig. 2e) during postnatal 


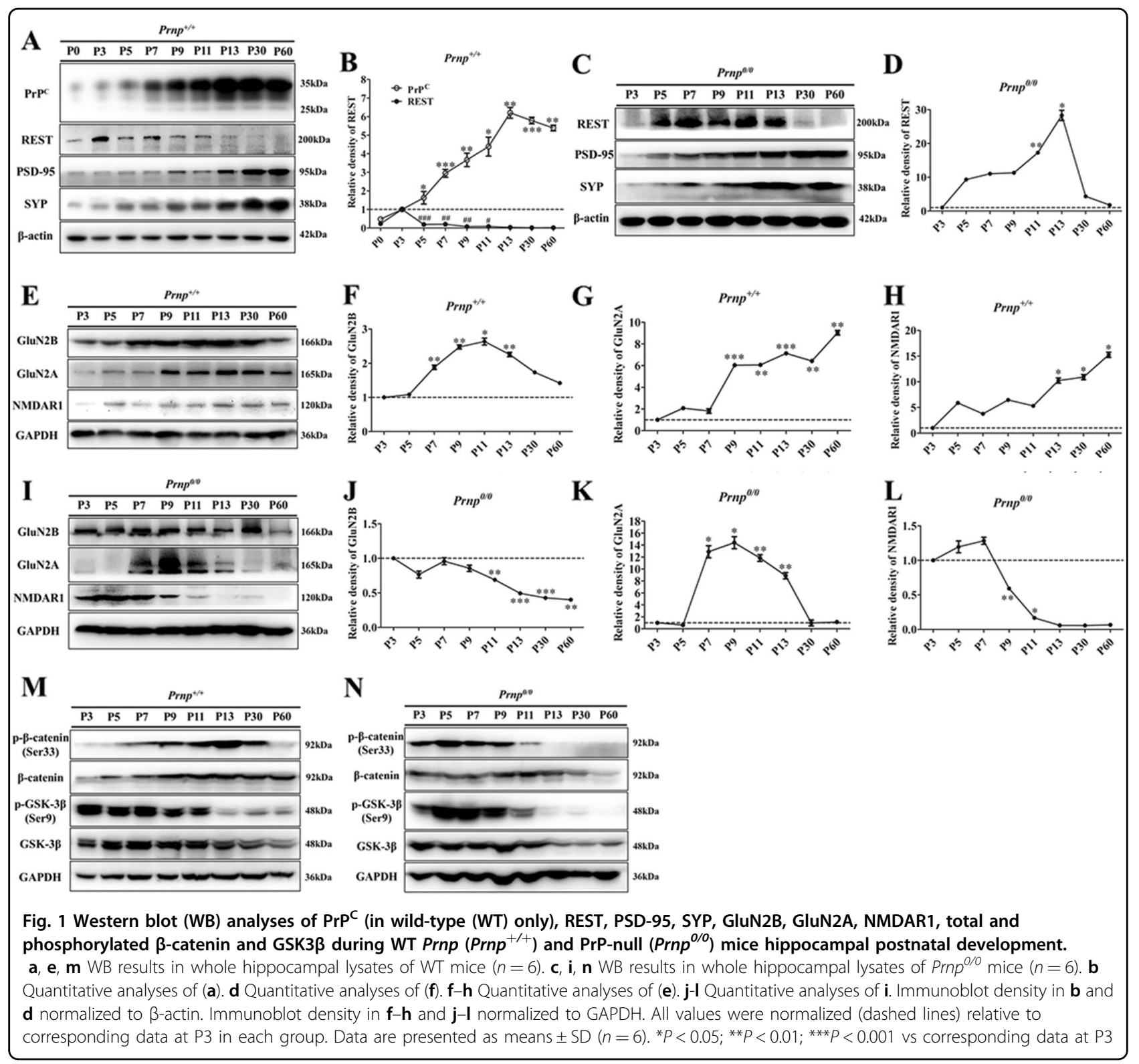

development (Fig. 2a). NMDAR1 expression was higher from P3 to P9 but decreased remarkably after P30 (Fig. 2f). Levels of SYP and PSD-95, the pre- and postsynaptic markers, showed a consistent upward trend and were not significantly different between the two groups.

We recently demonstrated that $\beta$-catenin were expressed in parallel with REST under physiological ${ }^{22}$ and pathological conditions in LRP6-Wnt- $\beta$-catenin signaling pathways $^{23,24}$. Conversely, total GSK3 $\beta$ protein has an inverse relationship with REST ${ }^{24}$. Our results reveal that: (1) total $\beta$-catenin and $\mathrm{p}-\beta$-catenin $(\mathrm{Ser} 552) /$ total $\beta$ catenin protein had different expression patterns between WT and PrP-null mice: the former remained relatively high after P7 (Fig. 1m, Fig. S1E, and Fig. S1F), whereas the latter was more highly expressed at the beginning of P3 (Fig. 1n, Fig. S1I, and Fig. S1J). (2) Comparing WT and $P r n p^{0 / 0}$ mice, total $\beta$-catenin was still more highly expressed in the $\operatorname{Prnp}^{0 / 0}$ group, and $\mathrm{p}-\beta$ catenin (Ser552)/total $\beta$-catenin protein was generally more highly expressed in the latter, except at P9, but significantly decreased at P60 (Fig. 2b, g, h). (3) Although total GSK3 $\beta$ protein and p-GSK3 $\beta$ (Ser9)/total GSK3 $\beta$ protein had similar expression patterns in both groups (Fig. 1m, Fig. S1G, and Fig. S1H; Fig. 1n, Fig. S1K, and Fig. S1L), GSK3 $\beta$ protein levels were lower in $\operatorname{Prnp}^{0 / 0}$ mice except at P11, and p-GSK3 $\beta$ (Ser9)/total GSK3 $\beta$ protein was higher in the latter until P60. These findings are consistent with the state of REST in different groups. 


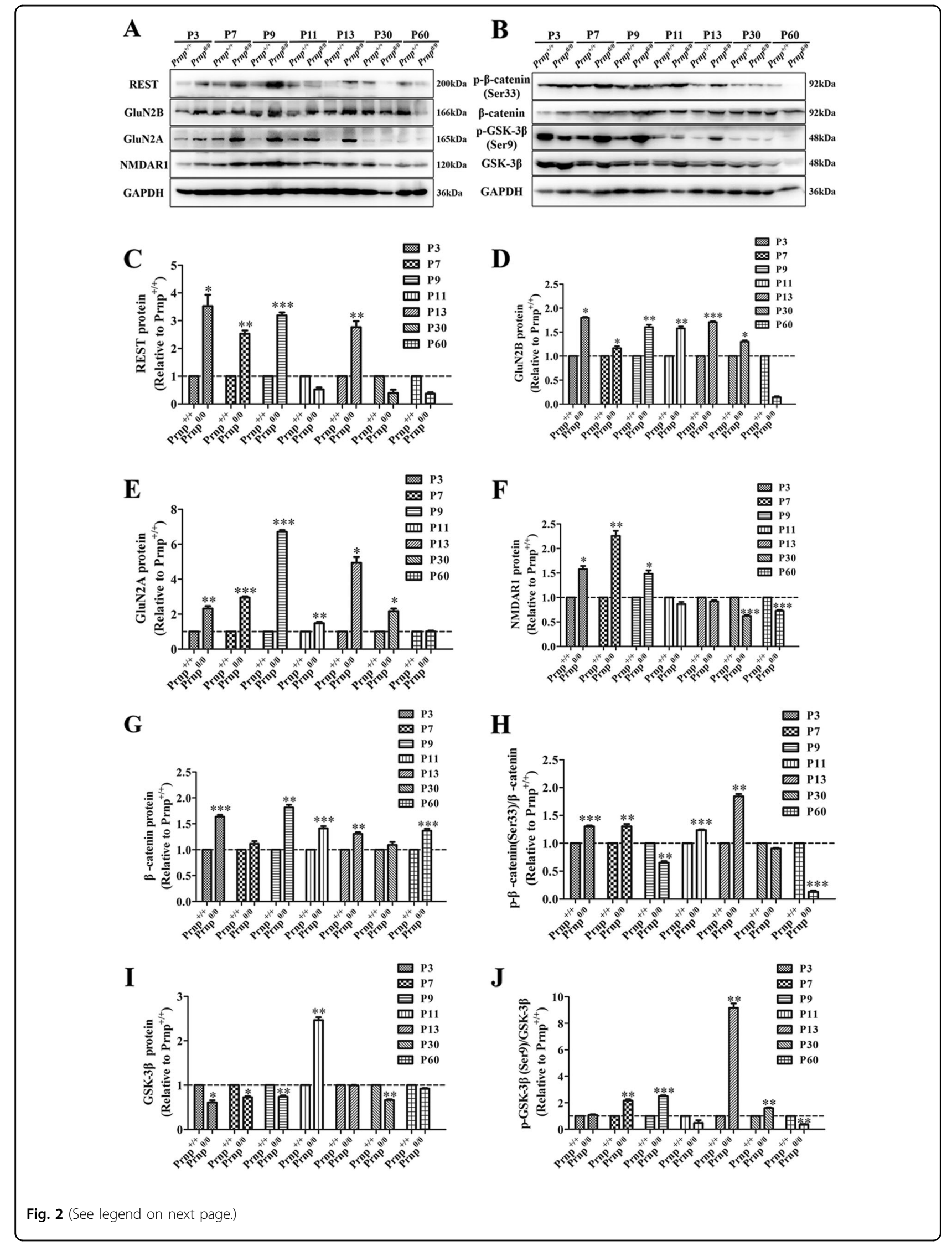


(see figure on previous page)

Fig. 2 WB analyses of REST and associated proteins to compare $\operatorname{Prnp}^{+/+}(n=6)$ with $\operatorname{Prnp}^{0 / 0}(n=6)$ mice hippocampal postnatal

development. a Immunoblot of REST, GluN2B, GluN2A, and NMDAR1. b Immunoblot of total and phosphorylated $\beta$-catenin and GSK3 $\beta$ proteins. c-f Quantitative analyses of (a). $\mathbf{g}$-j Quantitative analyses of (b). Immunoblot density in $\mathbf{c}-\mathbf{g}$ and $\mathbf{i}$ normalized to GAPDH and expressed as the ratio to GAPDH density. Immunoblot density in $\mathbf{h}$ and $\mathbf{j}$ showing the quantification of $\beta$-catenin (Ser33)/total $\beta$-catenin protein, GSK3 $\beta$ (Ser9)/total GSK3 $\beta$ protein, total $\beta$-catenin and GSK3 $\beta$ protein normalized to GAPDH. All values were normalized (dashed lines) relative to corresponding data in the Prnp $^{+/+}$group. Data are presented as means \pm SD $(n=6)$. ${ }^{*} P<0.05 ;{ }^{* *} P<0.01 ;{ }^{* * *} P<0.001 \mathrm{vs} \mathrm{Prnp}^{+/+}$

Overall, $\operatorname{Prnp}^{0 / 0}$ mice exhibited REST overexpression and disordered postnatal developmental switching from GluN2B-to-GluN2A, together with overactivation of $\beta$ catenin and suppression of GSK3ß.

\section{$\operatorname{PrP}^{C}$ is essential for REST functional translocation}

Previous reports have shown that activation and translocation of REST is a universal feature in response to stressors $^{25}$. Nuclear REST is a key factor, not only for developmental switch of NMDARs under physiological conditions, but also for neuroprotection in neurodegenerative diseases, such as prion diseases ${ }^{23,24}$ and $\mathrm{AD}^{22}$. Thus, to further study the potential effect of $\operatorname{PrP}^{\mathrm{C}}$ on REST, we compared the expression and distribution of REST in primary cultured WT and Prnp ${ }^{0 / 0}$ hippocampal neurons by immunofluorescence (IF) and western blot (WB) analysis. In the WT group, $\operatorname{PrP}^{\mathrm{C}}$ colocalized with REST in the cytoplasm under normal conditions. $N$ methyl-D-aspartic acid (NMDA), a selective NMDAR agonist $(10 \mu \mathrm{M}, 24 \mathrm{~h})$, stimulated the accumulation of REST partly in synapses, and a larger increase of $\operatorname{PrP}^{\mathrm{C}}$ in the soma. Lithium chloride ( $\mathrm{LiCl})$, a selective REST agonist $(10 \mathrm{mM}, 48 \mathrm{~h})$, remarkably induced the nuclear translocation of REST (Fig. 3a, b) (Fig. S2), a result consistent with our previous report. However, in the absence of $\operatorname{PrP}^{\mathrm{C}}$, REST had very little response to the agonist and most of it located in the cytoplasm (Fig. 3a, c). Quantitative WB analysis revealed results consistent with IF (Fig. $3 \mathrm{~d}-\mathrm{i}$ ). Although total REST in the PrP-null group was 1.31-fold higher than in the WT group under normal conditions, total REST significantly decreased by $40.41 \%$ and $32.22 \%$ after exposure to NMDA and $\mathrm{LiCl}$, respectively (Fig. 3d, g). What's more, in the Prnp ${ }^{O / O}$ groups, compared with the control, total REST decreased significantly more, by $45.44 \%$ and $51.62 \%$ in the NMDA and LiCl, respectively (Fig. S3). Nuclear REST was markedly lost in each group when $\operatorname{PrP}^{\mathrm{C}}$ was absent (Fig. 3e, h). This demonstrates that the functional translocation of REST in response to NMDA and $\mathrm{LiCl}$ treatment depends on the presence of $\operatorname{PrP}^{\mathrm{C}}$.

\section{PrP ${ }^{C}$ is essential for REST-dependent NMDAR expression}

REST provides a regulatory hub that coordinately regulates multiple physiological and pathological pathways of neuronal development and neurological diseases in vitro and in vivo ${ }^{10}$. Although REST-dependent epigenetic remodeling is critical to ischemia-induced neuronal death $^{26}$, other reports reveal that overexpression of REST plays a critical neuroprotective role $^{22,24}$. Therefore, we examined whether overexpression or knockdown of REST could functionally recover NMDARs expression in the absence of $\operatorname{PrP}^{C}$. Thus, we examined the expression of GluN2B, GluN2A and NMDAR1 when REST was blocked or overexpressed in WT or PrP-null neurons. Importantly, overexpression of REST significantly increased the level of GluN2B by 7.47-fold compared with the HA vector control in the WT group. Conversely, knockdown of REST markedly suppressed the level of GluN2B by $32.16 \%$ but increased the expression of Glu2A 1.57-fold compared with WT control (Fig. 4a, b). By contrast, neither knockdown nor overexpression of REST had any significant effect on NMDAR expression (Fig. 4a, b). This strongly suggests that $\operatorname{PrP}^{C}$ is essential for RESTdependent NMDAR expression, especially for GluN2B. Additionally, the number of normal mitochondria, mediated by the neuroprotective function of $\mathrm{REST}^{24}$, decreased (Fig. 4e, f). Even though REST was overexpressed, compared with the WT group, the mitochondrial number decreased by $7.92 \%$ (Fig. $4 \mathrm{e}, \mathrm{f}$ ) in the Prnp ${ }^{0 / 0}$ group, implying that the presence of $\operatorname{PrP}^{\mathrm{C}}$ might have an effect on the REST-mediated density of mitochondria.

\section{REST effects on mitochondria partially depend on $\operatorname{PrP}^{C}$}

It has been shown that $A \beta$ induces an extrasynaptic NMDAR-dependent increase in nitric oxide, leading to mitochondrial dysfunction and synapse deficiency ${ }^{27,28}$. Overexpression of REST in primary cortical neurons alleviates neurotoxicity peptide (PrP106-126)-induced neuronal oxidative stress and mitochondrial damage ${ }^{24}$. Importantly, loss of $\mathrm{PrP}^{\mathrm{C}}$ results in decreased mitochondrial numbers and abnormal mitochondrial morphol$\mathrm{ogy}^{29}$. In light of these previous studies, we further explored the potential relationship of $\operatorname{PrP}^{\mathrm{C}}$ with RESTregulated mitochondrial numbers and distribution.

The NMDAR antagonist dizocilpine maleate (MK-801) improves mitochondrial function and energy status ${ }^{30}$, linking NMDAR activation and mitochondrial function ${ }^{31}$. WT and Prnp $^{0 / 0}$ hippocampal neurons were treated with either NMDA $(10 \mu \mathrm{M}, 24 \mathrm{~h})$ or MK-801 (Dizocilpine) $(10 \mu \mathrm{M}, 24 \mathrm{~h})$ to observe the density and distribution of 


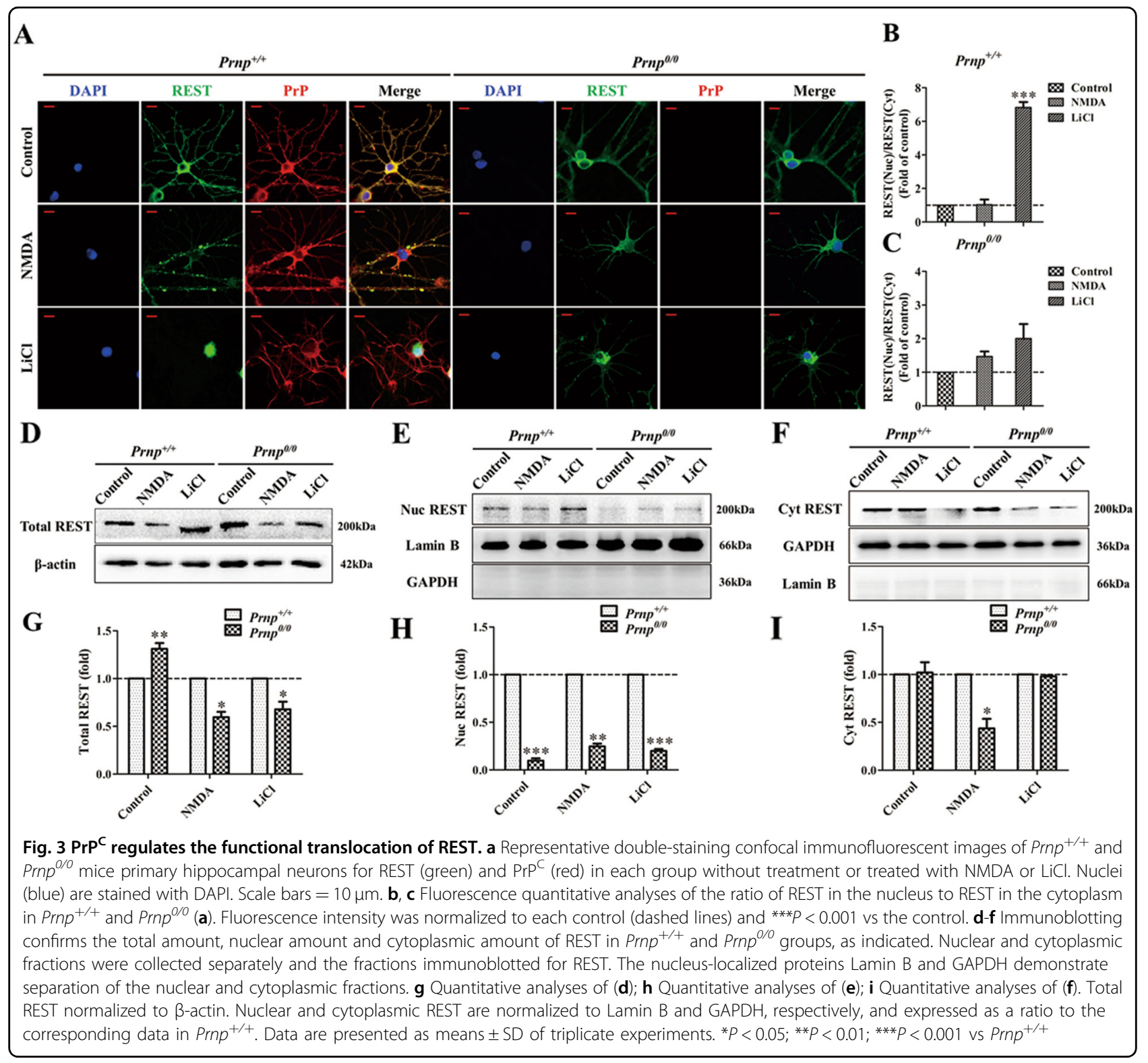

mitochondria (Fig. 5a-c). In both the WT and Prnp $0 / 0$ groups, NMDA significantly decreased mitochondrial numbers by $60.49 \%$ and $63.01 \%$, respectively, compared with controls. MK-801 markedly increased mitochondrial numbers in the WT and Prnp ${ }^{0 / 0}$ groups by 1.61 -fold and 1.53-fold, respectively, relative to corresponding control.

Exposure of hippocampal neurons to NMDA significantly increased the number of cells harboring clustered perinuclear mitochondria in both WT and Prnp ${ }^{0 / 0}$ groups, whereas the number in the latter group increased slightly. As overexpression of REST had a diminished effect on mitochondrial numbers in the $P r n p^{0 / 0}$ group compared with the WT group, (mitochondrial number decreased by $7.92 \%$ ), through a $\operatorname{PrP}^{\mathrm{C}}$ rescue experiment we directly explored the role of $\operatorname{PrP}^{\mathrm{C}}$ in REST-regulated mitochondria. A REST-HA vector was co-transfected with a HA vector into WT or Prnp ${ }^{0 / 0}$ hippocampal neurons, or co-transfected with a PrP-HA vector into Prnp ${ }^{0 / 0}$ hippocampal neurons. As expected, co-overexpression of $\mathrm{PrP}^{\mathrm{C}}$ and REST in Prnp ${ }^{0 / 0}$ cultures partially restored mitochondrial numbers compared with the Prnp ${ }^{0 / 0}$ group transfected with REST alone (Fig. 5d, e). Moreover, the number of cells harboring clustered perinuclear mitochondria also significantly decreased when $\operatorname{PrP}^{\mathrm{C}}$ and REST were co-transfected into $P r n p^{0 / 0}$ mice (Fig. 5d, f).

\section{PrPC plays a critical role in REST-regulated GluN2A and GluN2B expression}

Previous reports have demonstrated that native $\operatorname{PrP}^{C}$ mediates an important neuroprotective role through its 


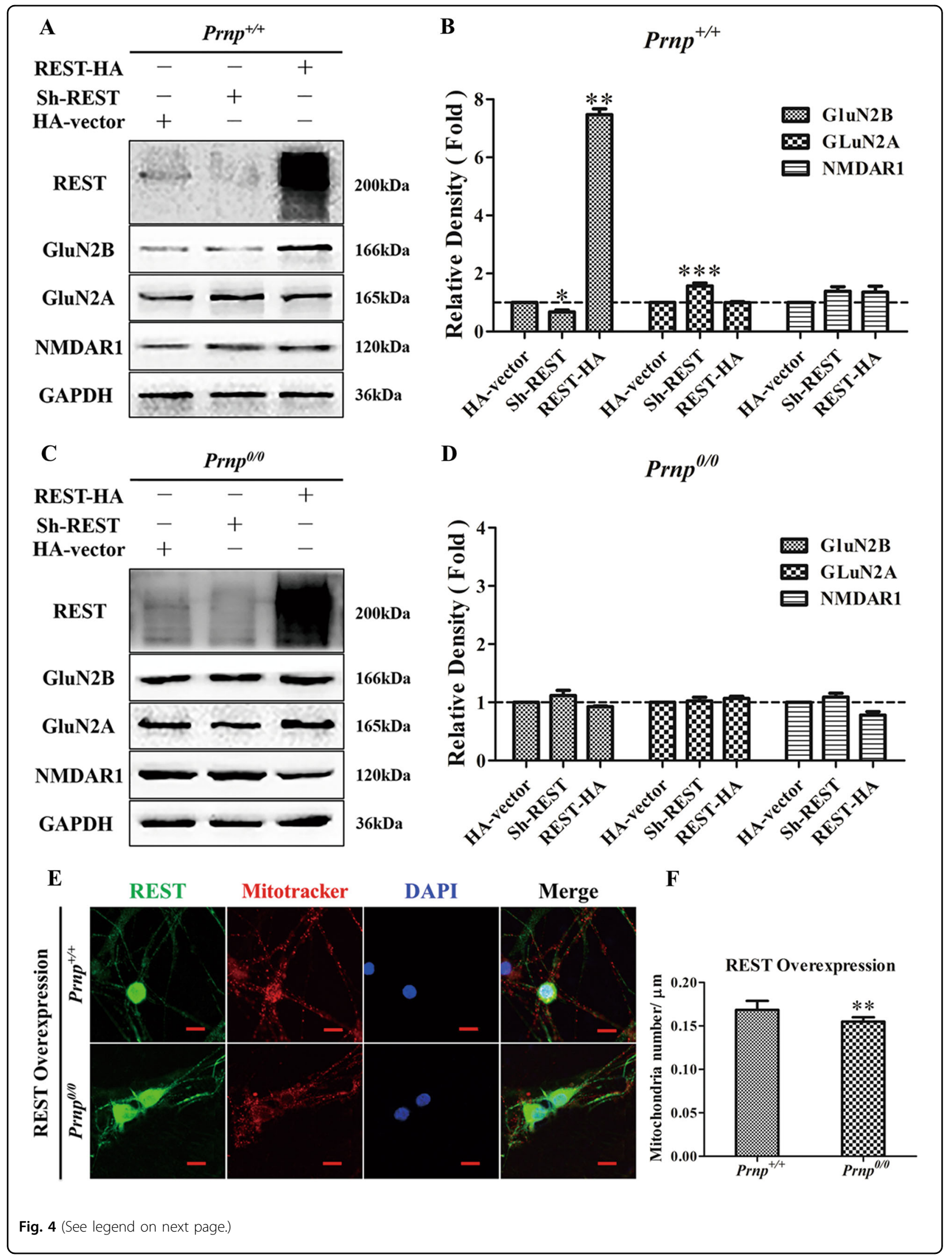


(see figure on previous page)

Fig. $4 \mathrm{PrP}^{\mathrm{C}}$ is essential for REST-regulated expression of NMDARs and mitochondrial numbers. Prnp ${ }^{+/+}$a and Prnp $p^{0 / 0} \mathbf{c}$ mice primary hippocampal neurons were transfected with a control HA vector, or REST shRNA (REST knockdown) or REST-HA vector (REST overexpression). Cellular proteins were immunoblotted for REST, GluN2B, GluN2A and NMDAR1. b and $\mathbf{d}$ quantitative analyses of $\mathbf{a}$ and $\mathbf{c}$, respectively. Immunoblot density in $\mathbf{b}$ and $\mathbf{d}$ were normalized to GAPDH and expressed as the relative density to the HA vector (dashed lines) in each group. ${ }^{*} P<0.05 ;{ }^{* *} P<0.01 ;{ }^{* * *} P<$ 0.001 in (b) vs the HA vector group. e Confocal immunofluorescence labeling for total REST (green), including exogenous (overexpression of REST) and endogenous REST, and mitochondria (MitoTracker Red) in Prnp ${ }^{+/+}$and Prnp ${ }^{/ / 0}$ hippocampal neurons. Nuclei (blue) were stained with DAPI. Scale bars $=10 \mu \mathrm{m}$. $\mathbf{f}$ Quantification of mitochondrial number (e) in a segment of neuronal process $200 \mu \mathrm{m}$ length beginning from the cell body of neurons $(n=30)$. Experiments were performed in triplicate. ${ }^{* *} P<0.01 ;{ }^{* * *} P<0.001 \mathrm{vs}^{\text {Prnp }}{ }^{+/+}$

ability to inhibit NR2D subunits ${ }^{16}$. Although NR2B subunits did not immunoprecipitate with $\operatorname{PrP}^{C}$ in that study, $\operatorname{PrP}^{\mathrm{C}}$ may interact with NMADRs subunits through other and/or indirect ways, an interaction that needs further exploration. So, to examine whether there is an association between NR2 subunits and $\operatorname{PrP}^{C}$, we analyzed the surface expression of Glu2A, Glu2B, and in WT hippocampal neurons using immunolabel reactivity (Fig. 6a). Although Glu2A expression was slight, Glu2B and $\operatorname{PrP}^{C}$ could well localize in the place where Glu2A existed (Fig. 6b). We then stained total Glu2A and total Glu2B along dendritic processes in WT and Prnp ${ }^{0 / 0}$ neurons. The specific dendritic marker, microtubule-associated protein (MAP2) was used to reveal dendrites by IF. Glu2A-positive and Glu2B-positive puncta along processes were quantitatively analyzed. $\mathrm{PrP}^{\mathrm{C}}$ rescue experiments were also used to explore the function of $\operatorname{PrP}^{\mathrm{C}}$ by IF and WB. First, WT cultures were transfected with three different short hairpin RNA (shRNA)-mediated PrP knockdown vectors $\left(\right.$ Prnp $^{+/+}+$Sh-PrP) and compared with the PrP-null cultures $\left(P r n p^{O / 0}\right)$ to exclude the interfering factor of genetic background in the knockout mice. In a second experiment, PrP-null cultures were transfected with HA-PrP vector $\left(\operatorname{Prnp}^{0 / 0}+\mathrm{HA}-\operatorname{PrP}\right)$ to observe the function of full-length $\operatorname{PrP}^{\mathrm{C}}$. Third, PrP-null cultures were transfected with a WT $\operatorname{PrP}^{\mathrm{C}}$ vector $^{32}\left(\operatorname{Prnp}^{0 /}\right.$ $\left.{ }^{o}+\mathrm{WT}\right)$ and compared with the HA-PrP vector group to remove the potential influence of the $\mathrm{HA}$ tag to the location of $\mathrm{PrP}^{\mathrm{C}}$ and to further confirm the function of full-length $\operatorname{PrP}^{\mathrm{C}}$. In a final experiment, PrP-null cultures were transfected with a $\operatorname{PrP}^{\mathrm{C}}$ mutant $(\mathrm{D} 177 \mathrm{~N}$ point mutation $)^{32}\left[\operatorname{Prnp}^{0 / 0}+\operatorname{PrP}(\mathrm{D} 177 \mathrm{~N})\right]$ that is less efficiently trafficked to the surface than the WT PrP and accumulates in the cytoplasm even without proteasome inhibition. These cultures were compared with the WT $\operatorname{PrP}^{\mathrm{C}}$ to further confirm the role of full-length $\operatorname{PrP}^{\mathrm{C}}$. Remarkably, both in the Prnp ${ }^{+/+}+$Sh-PrP group and in the $\operatorname{Prnp}^{O / O}$ group, Glu2A puncta significantly decreased by $37.70 \%$ and $52.17 \%$ relative to the WT group (23.07 \pm 0.05 per $100 \mu \mathrm{m}$ of dendrites), respectively. Conversely, Glu2B was present in more continuously abundant puncta, increased 1.25-fold (Prnp ${ }^{+/+}+$Sh-PrP) and 1.30fold $\left(\right.$ Prnp $\left.^{O / O}\right)$ over the WT group $(33.67 \pm 0.06$ per 100 $\mu \mathrm{m}$ of dendrites) (Fig. $6 \mathrm{c}, \mathrm{d}$ ). On the other hand, overexpression of HA-PrP vector or WT PrP vector had similar effects. They both partly restored the densities of GluN2A puncta $\left(\right.$ Prnp $^{0 / 0}$ versus Prnp $^{0 / 0}+$ HA-PrP: 11.01 \pm 0.07 versus $20.33 \pm 0.09$ per $100 \mu \mathrm{m}$ of dendrites; $P r n p^{0 /}$ ${ }^{\circ}$ versus Prnp $^{0 / O}+$ WT PrP: $11.01 \pm 0.07$ versus $23.03 \pm$ 0.05 per $100 \mu \mathrm{m}$ of dendrites) and reduced the densities of GluN2B puncta $\left(\right.$ Prnp $^{O / O}$ versus Prnp ${ }^{0 / 0}+$ HA-PrP: 43.67 \pm 0.04 versus $35.07 \pm 0.07$ per $100 \mu \mathrm{m}$ of dendrites; Prnp $^{0 /}$ ${ }^{\circ}$ versus $\operatorname{Prnp}^{0 / 0}+\mathrm{WT}$ PrP: $43.67 \pm 0.04$ versus $34.33 \pm$ 0.05 per $100 \mu \mathrm{m}$ of dendrites). However, the D177N mutant had no significant effect on the expression of GluN2A $(12.33 \pm 0.07$ per $100 \mu \mathrm{m}$ of dendrites $)$ or GluN2B (42.83 \pm 0.03 per $100 \mu \mathrm{m}$ of dendrites) (Fig. $6 \mathrm{f}, \mathrm{g}$ ). Total neurite length (the cumulative length of all neurites of a single neuron) was not significantly different in the groups tested $(n=30$ randomly selected neurons per coverslip within each experiment. Each experiment was repeated with, at least, three independent cultures). The average length of neurites in each group is shown in Figure. 6e, h.

Consistently, quantitative WB analysis revealed the following. (1) Knockdown of $\mathrm{PrP}^{\mathrm{C}}$ in WT culture remarkably induced the expression of REST (increased to 17.14-fold of the Prnp ${ }^{0 / O}$ group), stimulated the level of GluN2B (increased to 20.68-fold of the $\operatorname{Prnp}^{0 / 0}$ group) and suppressed the level of GluN2A (decreased to $63.54 \%$ of the Prnp ${ }^{0 / 0}$ group). However, NMDAR1 expression was not significantly different, and negative control vector (NC) showed similar results to control group (Fig. 6i, l). (2) $\mathrm{PrP}^{\mathrm{C}}$ overexpression significantly inhibited the expression of REST (decreased to $21.94 \%$ of the Prnp ${ }^{0 / 0}$ group), contributing to the suppression of GluN2B (decreased to $39.50 \%$ of the $\operatorname{Prnp}^{0 / 0}$ group) and the promotion of GluN2A (increased to 2.33-fold of the PrP-null group). NMDAR1 expression was not significantly different in the two groups (Fig. 6j, m). (3) Both HA-PrP vector and WT PrP vector had similar degrees of functional action to REST, GluN2B and GluN2A. However, PrP (D177N) mutant failed to recover the expression of these proteins in Prnp $^{O / O}$ culture (Fig. 6k, n). Overall, our data indicate a critical and novel relationship between full-length $\operatorname{PrP}^{\mathrm{C}}$, GluN2A and GluN2B. This is mediated by REST to maintain the correct proportions of NMDAR subunits. 

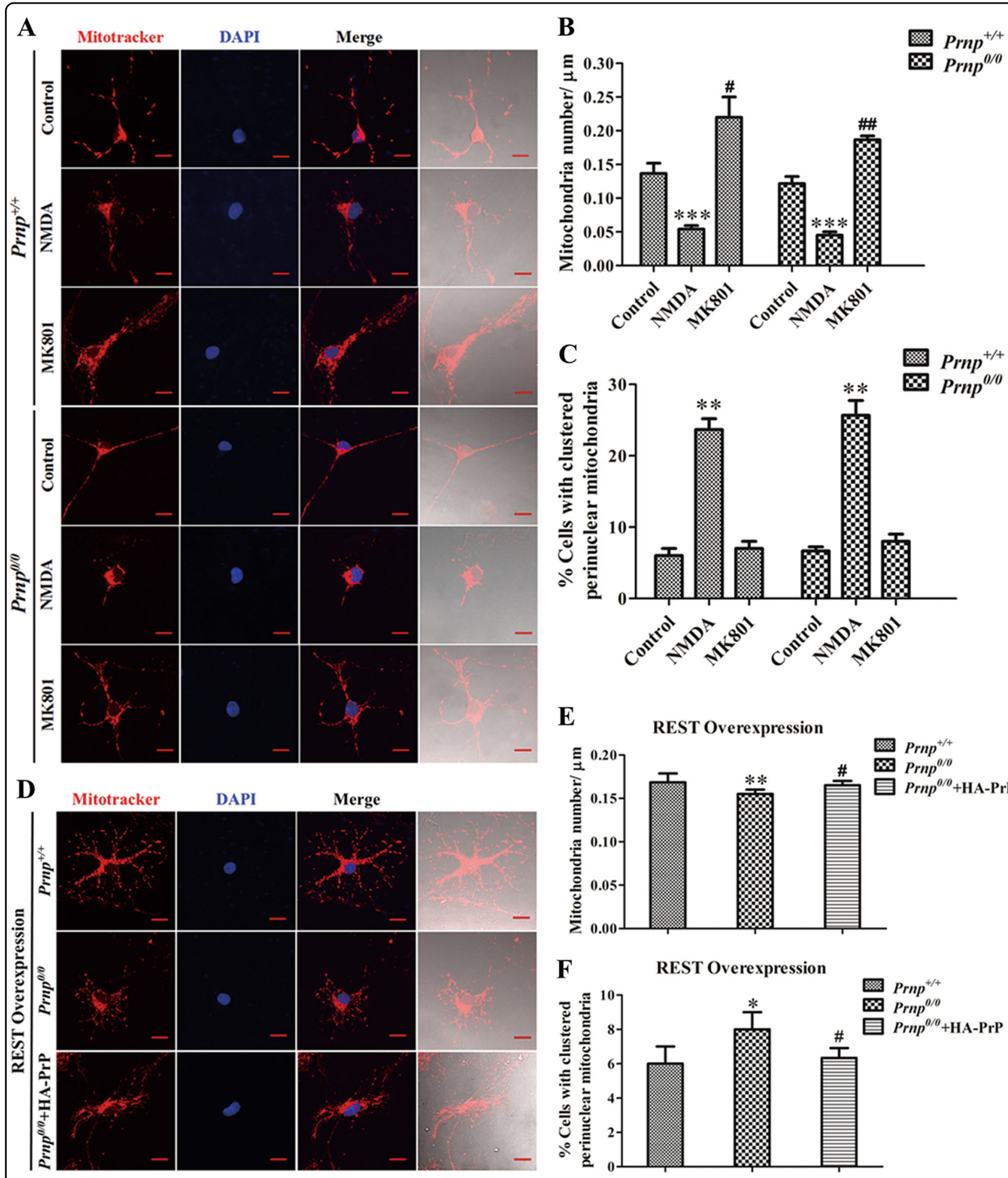

Fig. 5 (See legend on next page.) 
(see figure on previous page)

Fig. $5 \operatorname{PrP}^{C}$ effects on the density and distribution of mitochondria. a Following treatment with NMDA or MK-801 (or no treatment), Prnp ${ }^{+/+}$and $\mathrm{Prnp}^{0 / 0}$ mice primary hippocampal neurons were stained with MitoTracker Red to visualize mitochondria and analyzed by fluorescence microscopy. Nuclei (blue) are stained with DAPI. Scale bars $=10 \mu \mathrm{m}$. b Quantification of mitochondrial number (a) in a segment of neuronal process $200 \mu \mathrm{m}$ in length beginning from the cell body of neurons $(n=30) .{ }^{\#} P<0.05 ;{ }^{\# \#} P<0.01 ;{ }^{* *} P<0.001$ vs corresponding control. c Quantification analysis of (a) to confirm the number of cells harboring perinuclearly clustered mitochondria. For this quantification, mitochondria of at least 500 cells per experiment were determined in a blinded manner. Quantifications were based on triplicates of at least three independent experiments. ${ }^{* *} P<0.01$ vs corresponding control. d Co-transfection of $\mathrm{PrP}^{C}$ and REST rescued the density and distribution of mitochondria. Scale bars $=10 \mu \mathrm{m}$. e Quantification of mitochondrial number (d) in a segment of neuronal process $200 \mu \mathrm{m}$ in length beginning from the cell body of neurons ( $n=30$ ). ${ }^{*} * P<0.01$ vs Prnp ${ }^{+/+} .{ }^{*} P<0.05$ is $P r n p^{0 / 0}+$ HA-PrP vs Prnp ${ }^{0 / 0}$. $\mathbf{f}$ Quantification analysis of (d) to confirm the number of cells harboring perinuclearly clustered mitochondria. For this quantification, mitochondria of at least 500 cells per experiment were determined in a blinded manner. Quantifications were based on triplicates of at least three independent experiments. ${ }^{*} P<0.05$ vs $\operatorname{Prnp}{ }^{+/+} .{ }^{*} P<0.05$ is $\operatorname{Prnp}{ }^{0 / 0}+\mathrm{HA}-\operatorname{PrP}$ vs $\operatorname{Prnp}{ }^{0 / 0}$

\section{Discussion}

The importance of a developmental switch maintaining the correct ratio of GluN2B-to-GluN2A

NMDARs are necessary regulators of brain plasticity ${ }^{1}$. During the development of synapse structure and function, they transform precise patterns of neuronal activity into long-term changes that are thought to underlie higher cognitive functions ${ }^{33}$. Moreover, NMDARs switch their subunits from predominantly GluN2B to primarily GluN2A during early postnatal development ${ }^{34}$. This subunit switch is evolutionarily conserved from amphibians to mammals and occurs all over the CNS during a time window coinciding with synapse growth and neuronal circuitry refinement ${ }^{1,33}$. However, the mechanisms responsible for the GluN2B-to-GluN2A subunit exchange have yet to be fully defined ${ }^{12}$. In neurodegenerative diseases, recent studies also indicate that GluN2B-containing NMDARs have an essential role in mediating the adverse effects of $A \beta^{27}$. GluN2B antagonists can rescue $A \beta-$ induced damage of long-term potentiation and synaptic impairment ${ }^{35}$. However, all of the clinical trials of firstgeneration NMDAR antagonists were disappointing as a result of unendurable side-effects and short therapeutic windows $^{36}$. Another potential limitation is the lack of subunit selectivity of the drugs ${ }^{2,35}$. GluN2B-specific antagonists offer significant neuroprotection with a better side-effect profile. Conversely, activation of GluN2A may exhibit pro-survival effects ${ }^{37}$ via CREB signaling, although the neuroprotective role of GluN2A is still controversial $^{38,39}$. Additionally, in patients with Parkinson's disease, the degeneration of nigral dopaminergic neurons gives rise to overactivation of glutamatergic projections ${ }^{40,41}$. In the striatal membrane of 1-3,4-dihydroxyphenylalanine (1-DOPA)-treated dyskinesia animals, the increased synaptic abundance of GluN2A and redistribution of GluN2B from synaptic to extrasynaptic regions demonstrate that selectively targeting specific NMDARs might be more hopeful ${ }^{42}$. Understanding the precise molecular mechanisms responsible for the GluN2B-to-GluN2A exchange could provide new perspectives for the development of therapeutic strategies.
PrP ${ }^{C}$ plays a novel and critical role in the REST-dependent developmental switch in synaptic NMDA receptors

During embryogenesis in pluripotent stem cells and neural progenitors, REST is a widely expressed genesilencing factor. REST plays an important role for synaptic function via epigenetic remodeling by silencing coding and noncoding neuronal genes ${ }^{10}$. At the gene level, REST takes part in the postnatal switch in synaptic NMDARs by reducing GluN2B expression through epigenetic remodeling of Grin $2 b^{43}$. Some questions remain unanswered, such as what mechanism turns on REST expression in differentiated neurons, and which factor regulates the long-term increase in GluN2A expression during postnatal development.

Mature $\mathrm{PrP}^{\mathrm{C}}$ is a glycoprotein attached by a carboxyl (C)-terminal glycosylphosphatidylinositol (GPI) anchor to the extracellular leaflet of the plasma membrane ${ }^{44} \cdot \operatorname{PrP}^{C}$ can undergo different types of physiological cleavage, producing $\mathrm{N} 2$ and $\mathrm{C} 2$ fragments ${ }^{13}$. $\mathrm{PrP}^{\mathrm{C}}$ contacts with, and signals through, multiple cell surface proteins and signaling pathways. This highlights the need for a better understanding of the mechanisms of $\mathrm{PrP}^{\mathrm{C}}$ interaction with its binding factors, both physiologically and pathologically ${ }^{44}$. Comparing WT and Prnp ${ }^{0 / 0}$ revealed that $\operatorname{PrP}^{\mathrm{C}}$ expression at synapses contributes to hippocampal synaptic function and exhibits neuroprotection by regulating neuronal excitability. In particular, $\operatorname{PrP}^{C}$ requires copper to facilitate S-nitrosylation-mediated NMDAR suppression $^{17}$. However, GluN2B subunits did not immunoprecipitate with $\mathrm{PrP}^{\mathrm{C}}$ in a previous study ${ }^{16}$ and no studies have yet explored the relationship between $\operatorname{PrP}^{\mathrm{C}}$ and GluN2A. PrP ${ }^{\mathrm{C}}$ might interact with GluN2B through indirect ways, an aspect needing further research. Nucleocytoplasmic transport is thought to be important for REST as a transcriptional repressor regulating neuronal gene expression ${ }^{22,25}$. In this study, nuclear REST was markedly lost in the absence of $\operatorname{PrP}^{\mathrm{C}}$, demonstrating that the functional translocation of REST in response to NMDA and $\mathrm{LiCl}$ treatment depends on the presence of $\operatorname{PrP}^{C}$. Overexpression of exogenous $\operatorname{PrP}^{C}$ rescued excessive REST induced GluN2A and GluN2B imbalance by 


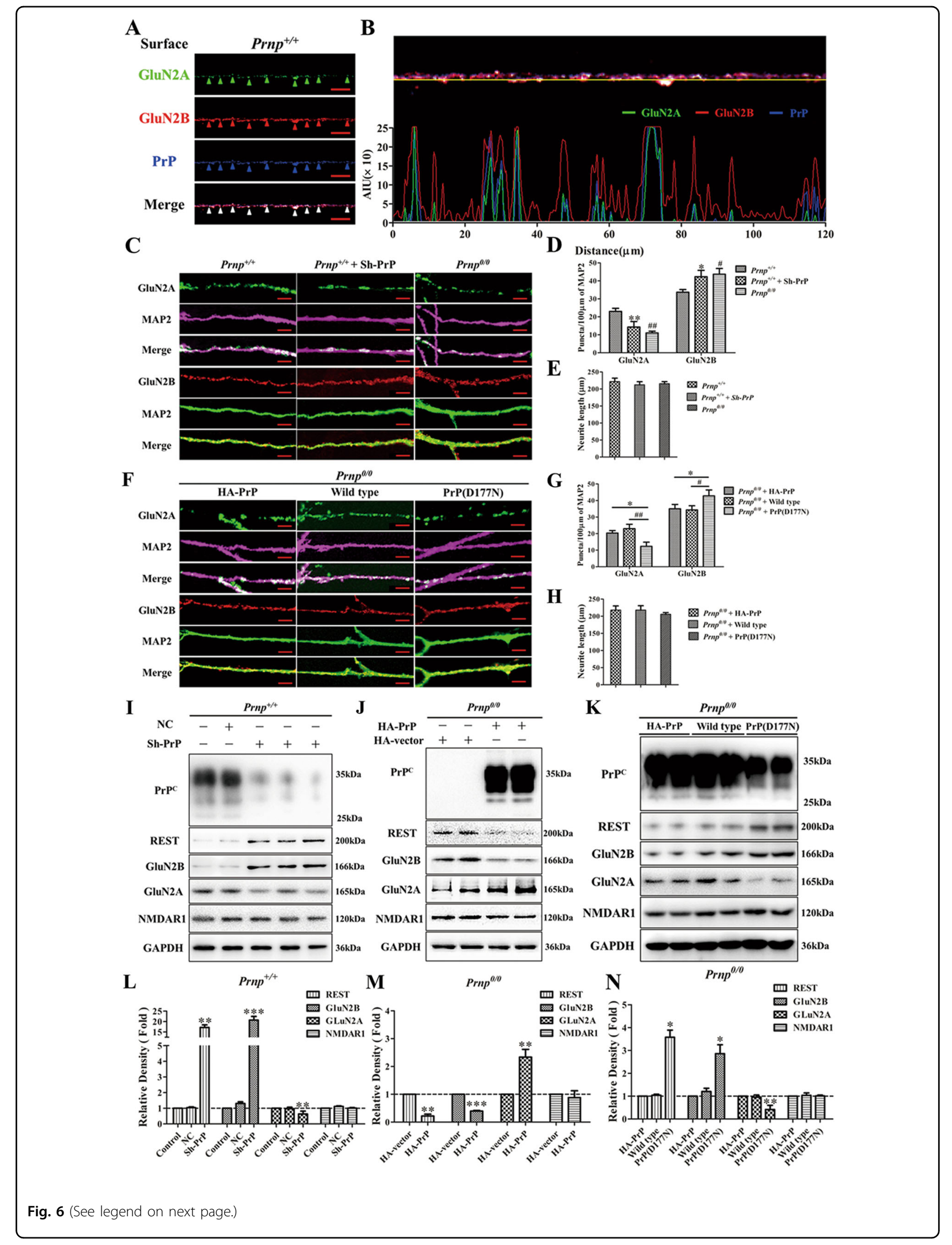


(see figure on previous page)

Fig. 6 PrPC plays a critical role in REST-regulated expression levels of GluN2A and GluN2B. a Triple-labeled WT mouse hippocampal neurons for GluN2A (green), GluN2B (red) and PrPC (blue) along dendritic processes. The arrowheads highlight examples of clear colocalization of GluN2A (green), GluN2B (red), and PrPC (blue). Scale bars $=10 \mu \mathrm{m}$. The yellow line in the top panel of (b) indicates the position in (a) of the line scan shown in the bottom panel of (b). $\mathbf{c}$-e Knockdown of PrPC disturbed the density of GluN2A and GluN2B. $\mathbf{f}-\mathbf{h}$ Overexpression of full-length $\operatorname{PrP}^{\mathrm{C}}$ restores Prnp ${ }^{0 / 0}$ induced disorder of GluN2A and GluN2B. c, $\mathbf{f}$ Microtubule-associated protein (MAP2) is the specific dendritic maker. GluN2A (green) protein puncta along processes (MAP2, magenta) and GluN2B (red) protein puncta along processes (MAP2, green) in neurons of Prnp ${ }^{+/+}$, Prnp $^{+/+}+$Sh-PrP and Prnp ${ }^{0 / 0}$, or Prnp ${ }^{0 / 0}$ culture transfected with HA-PrP vector, wild-type PrP vector or PrP(D177N) vector. Scale bars $=10 \mu \mathrm{m}$. $\mathbf{d}, \mathbf{g}$ Quantifications of GluN2A and GluN2B puncta density are normalized to $100 \mu \mathrm{m}$ neurite length, as assessed by MAP2 staining. In $(\mathbf{d}),{ }^{*} P<0.05 ;{ }^{* *} P<0.01$ is $P r n p^{+/+}+$ Sh-PrP vs Prnp ${ }^{+/+},{ }^{\#} P<0.05 ;{ }^{\# \#} P<0.01$ is Prnp ${ }^{0 / 0}$ vs $\operatorname{Prn} p^{+/+}$. In (g), ${ }^{*} P<0.05$ is $\operatorname{Prn} p^{0 / 0}+\operatorname{PrP}(\mathrm{D} 117 \mathrm{~N})$ vs $\operatorname{Prn} p^{+/+},{ }^{\#} P<0.05 ;{ }^{\# \#} P<0.01$ is $\operatorname{Prnp}{ }^{0 / 0+} \operatorname{PrP}$ (D117N) vs Prnp ${ }^{0 / 0+}$ wild-type PrP. e, h Average neurite length for each randomly tested neuron in each group $(n=30)$. i Immunoblot of REST, GluN2A, and GluN2B in Prnp ${ }^{+/+}$neurons pre-transfected with negative control vector (NC) or three separate PrPC shRNAs (Sh-PrP; each lane represents a different shRNA). I Quantitative analyses of (i). $\mathbf{j}$ Immunoblot of REST, GluN2A, and GluN2B in Prnp ${ }^{0 / 0}$ neurons pre-transfected with HA vector or HA-PrP vector. $\mathbf{m}$ Quantitative analyses of (j). $\mathbf{k}$ Immunoblot of REST, GluN2A and GluN2B in Prnp ${ }^{0 / 0}$ neurons pre-transfected with HA-PrP vector, or wild-type PrP vector or $\operatorname{PrP}(\mathrm{D} 117 \mathrm{~N})$ mutant vector. $\mathbf{n}$ Quantitative analyses of (k). Immunoblot density normalized to GAPDH and expressed as a relative density to the control group in (i), or to the HA vector-transfected group in (j), or to the HA-PrP vector-transfected group in (k). Data are presented as means \pm SD in triplicate experiments. In (I) ${ }^{* *} P<0.01 ;{ }^{* *} P<0.001$ vs control. In (m), ${ }^{* *} P<0.01$; ${ }^{* * *} P<0.001$ vs HA vector-transfected group. In (n), ${ }^{*} P<0.01 ;{ }^{* *} P<0.01$ vs HA-PrP vector-transfected group

increasing the expression of GluN2A and inhibiting the level of GluN2B in PrP-null neurons. To our knowledge, our study is the first to demonstrate that $\mathrm{PrP}^{\mathrm{C}}$-mediated REST-dependent expression of GluN2A and GluN2B contributes to maintain the correct subunit proportions of NMDARs and cellular homeostasis, deserving to be further explored as a novel and viable therapeutic target against dysfunctions of glutamatergic transmission.

\section{Materials and methods}

\section{Animals}

$\operatorname{PrnP}^{0 / 0}$ mice on a C57BL/6J $\times 129 \mathrm{~Sv}$ genetic background were kindly supplied by Dr. Charles Weiss$\operatorname{mann}^{45,46}$. Control C57BL/6J mice with no genomic modifications (WT), 6-8 weeks of age and weighing 18-25 g, were obtained from Beijing Experimental Animal Center. Mice were housed 3-4 per cage and under controlled environmental conditions $\left(21-23^{\circ} \mathrm{C} ; 40-60 \%\right.$ humidity; 12-h light/dark cycle) with free access to water and standard pelleted food. All animal experiments were conducted in accordance with the guidelines of Beijing Municipality on the Review of Welfare and Ethics of Laboratory Animals and approved by the Beijing Municipality Administration Office of Laboratory Animals (BAOLA).

\section{Plasmids and transfection}

The pCMV-HA-Rest vector of full-length REST (cat no. PPL50007-2a) $)^{24,25}$ was obtained from Public Protein/ Plasmid Library (Nanjing, China, GeneShare Technology, Co, Ltd). The pGPH1/GFP/Neo-REST-Mus shRNA vectors $^{24,25}$, the pGPH1/GFP/Neo-PRNP-Mus shRNA vectors (Table 1) and the negative control vector (NC) which has the same number of corresponding bases as shRNA-REST or shRNA-PRNP but does not target any known gene-were all obtained from GenePharma
(Suzhou, China). The full-length mouse prion protein (PRNP) complementary DNA (cDNA) was originally cloned from total brain of C57BL/6J mice by PCR. The primers were designed according to the gene sequence of Mus musculus prion protein (PRNP) mRNA in GenBank (Gene ID: 19122). Oligonucleotides 5'-CGGAATTCA TGGCGAACCTTGGCTACTG-3' (forward) and 5'GCCTCGAGTCACATGTGCTTCATGTTGGTTTTTC CCACGATCAGGAAGATGA-3' (reverse) were used to introduce EcoRI and XhoI sites flanking the cDNA (The underlined alphabets denote the "Restriction enzyme cutting sites" of EcoRI and XhoI, respectively.). The PCR product was cloned into vector pCMV-HA (Clontech, Kyoto, Japan) to generate plasmid pCMV-HA-PRNP (HA-PrP) by standard molecular biology techniques and confirmed by sequencing. All the primers were synthesized by Sangon Company (Shanghai, China). Full-length mouse PrP with 3F4 epitope (WT $\operatorname{PrP}^{\mathrm{C}}$ ) (Addgene plasmid \# 13917) and moPrP(3F4) D177N (Addgene plasmid \# 1319) were gifts from Susan Lindquist ${ }^{32}$. For

\section{Table 1 Sequences of REST-targeting shRNA(Sh-REST),} PRNP-targeting shRNA(Sh-PrP)

\begin{tabular}{ll}
\hline Name & Sequence $\left(\mathbf{5}^{\prime} \rightarrow \mathbf{3}^{\prime}\right)$ \\
\hline REST-mediated shRNA: & \\
Target sequence 1 & GCTGTGGCTACAATACCAACC \\
Target sequence 2 & GTGCAATTATGTGGCCTCTAA \\
Target sequence 3 & GGATTCACAGCGCTAAGAAGT \\
PRNP-mediated shRNA: & \\
Target sequence 1 & GCAACCGTACCCACCTCAGG \\
Target sequence 2 & GCCTATTACGACGGGAGAAGA \\
Target sequence 3 & GTGACTATGTGGACTGATG \\
\hline
\end{tabular}


transfection $^{23,24,47,48}$, cultured primary hippocampal neurons were washed with Opti-MEM (Gibco) and then transfected with the appropriate plasmids using the Lipofectamine $^{\mathrm{TM}}$ Ltx \& Plus ${ }^{\mathrm{TM}}$ Reagent (Thermo Fisher, Waltham, MA, USA) in Opti-MEM according to the manufacturer's instructions. The amounts of plasmids and reagents were $2 \mu \mathrm{g}$ and $3 \mu \mathrm{l}$ per 12-well, respectively. Forty-eight hours after transfection, cells were observed using an upright fluorescence confocal microscopy (Olympus, Tokyo, Japan) or subjected to immunoblot analyses.

\section{Statistical analysis}

All assays were performed at least three times. Data are expressed as means \pm S.D. For in vivo experiments, six hippocampal homogenates were separately collected and tested in each group. One-way ANOVA, followed by Dunnett's test was performed for whole hippocampal lysate experiments in Figure $1^{11}$. Two-way ANOVA was performed for Figure 2. Other comparisons for parametric data were made using Student's test or one-way ANOVA followed by post hoc Turkey's test or two-way ANOVA test using the SPSS software (version 13.0: SPSS Inc., Chicago, IL, USA), GraphPad Prism 5 software (La Jolla, CA, USA) and Image $J$ (National Institutes of Health, USA). $P<0.05$ was considered statistically significant ${ }^{24,25}$.

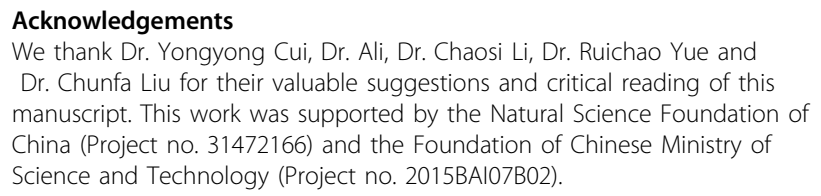

\section{Author details}

'The State Key Laboratories for Agrobiotechnology, Key Lab of Animal Epidemiology and Zoonosis, Ministry of Agriculture, National Animal Transmissible Spongiform Encephalopathy Laboratory, College of Veterinary Medicine, China Agricultural University, 100193 Beijing, China. ${ }^{2}$ Institute of Laboratory Animal Sciences, Chinese Academy of Medical Sciences (CAMS) and Comparative Medicine Center, Peking Union Medical Collage (PUMC), Key Laboratory of Human Disease Comparative Medicine, Ministry of Health, 100021 Beijing, China. ${ }^{3}$ Hebei Institute of Animal Science and Veterinary Medicine, 071000 Baoding, China

\section{Authors' contributions}

Conceived and designed the experiments: Z.Q.S. Performed the experiments: Z.Q.S. and W.Y. Analyzed the data: Z.Q.S. Wrote the paper: Z.Q.S. Edited the paper: Z.Q.S., W.Y., G.Y.C., X.M.Z., L.F.Y and D.M.Z. Contributed reagents/ materials/analysis tools: D.M.Z. All authors read and approved the final manuscript.

\section{Conflict of interest}

The authors declare that they have no conflict of interest.

\section{Publisher's note}

Springer Nature remains neutral with regard to jurisdictional claims in published maps and institutional affiliations.

Supplementary Information accompanies this paper at (https://doi.org/ 10.1038/s41419-018-0576-z).
Received: 11 January 2018 Accepted: 19 March 2018

Published online: 10 May 2018

\section{References}

1. Paoletti, P., Bellone, C. \& Zhou, Q. NMDA receptor subunit diversity: impact on receptor properties, synaptic plasticity and disease. Nat. Rev. Neurosci. 14, 383-400 (2013).

2. Traynelis, S. F. et al. Glutamate receptor ion channels: structure, regulation, and function. Pharmacol. Rev. 62, 405-496 (2010).

3. Paoletti, P. Molecular basis of NMDA receptor functional diversity. Eur. J. Neurosci. 33, 1351-1365 (2011)

4. Monyer, H., Burnashev, N., Laurie, D. J., Sakmann, B. \& Seeburg, P. H. Developmental and regional expression in the rat brain and functional properties of four NMDA receptors. Neuron 12, 529-540 (1994).

5. Dumas, T. C. Developmental regulation of cognitive abilities: modified composition of a molecular switch turns on associative learning. Prog. Neurobiol. 76, 189-211 (2005)

6. Espinosa, J. S., Wheeler, D. G., Tsien, R. W. \& Luo, L. Uncoupling dendrite growth and patterning: single-cell knockout analysis of NMDA receptor $2 \mathrm{~B}$. Neuron 62, 205-217 (2009).

7. Von Engelhardt, J. et al. Contribution of hippocampal and extra-hippocampal NR2B-containing NMDA receptors to performance on spatial learning tasks. Neuron 60, 846-860 (2008).

8. Gray, J. A. et al. Distinct modes of AMPA receptor suppression at developing synapses by GluN2A and GluN2B: single-cell NMDA receptor subunit deletion in vivo. Neuron 71, 1085-1101 (2011).

9. Lee, M., Yasuda, R. \& Ehlers, M. D. Metaplasticity at single glutamatergic synapses. Neuron 66, 859-870 (2010).

10. Song, Z., Zhao, D., Zhao, H. \& Yang, L. NRSF: an angel or a devil in neurogenesis and neurological diseases. J. Mol. Neurosci. 56, 131-144 (2015).

11. Rodenas-Ruano, A., Chávez, A. E., Cossio, M. J., Castillo, P. E. \& Zukin, R. S. RESTdependent epigenetic remodeling promotes the developmental switch in synaptic NMDA receptors. Nat. Neurosci. 15, 1382-1390 (2012).

12. Parsons, M. P. \& Raymond, L. A. Extrasynaptic NMDA receptor involvement in central nervous system disorders. Neuron 82, 279-293 (2014).

13. Black, Stefanie A. G. et al. Cellular Prion Protein and NMDA Receptor Modulation: Protecting against Excitotoxicity. Frontiers in Cell Dev. Biol. 2, article 45 (2014); e-pub ahead of print 27 April 2018.

14. Song, Z., Zhao, D. \& Yang, L. Molecular mechanisms of neurodegeneration mediated by dysfunctional subcellular organelles in transmissible spongiform encephalopathies. Acta Biochem. Biophy. Sin. 45, 452-464 (2013).

15. Soto, C. \& Satani, N. The intricate mechanisms of neurodegeneration in prion diseases. Trends Mol. Med. 17, 14-24 (2011).

16. Khosravani, H. et al. Prion protein attenuates excitotoxicity by inhibiting NMDA receptors. J. Cell Biol. 181, 551-565 (2008).

17. Gasperini, L., Meneghetti, E., Pastore, B., Benetti, F. \& Legname, G. Prion protein and copper cooperatively protect neurons by modulating NMDA receptor through S-nitrosylation. Antioxid. Redox Sign. 22, 772-784 (2015).

18. Borrelli, E., Nestler, E. J., Allis, C. D. \& Sassone-Corsi, P. Decoding the epigenetic language of neuronal plasticity. Neuron 60, 961-974 (2008).

19. Levenson, J. M. \& Sweatt, J. D. Epigenetic mechanisms in memory formation. Nat. Rev. Neurosci. 6, 108-118 (2005).

20. Tremblay, P., Bouzamondo-Bernstein, E., Heinrich, C., Prusiner, S. B. \& DeArmond, S. J. Developmental expression of PrP in the post-implantation embryo. Brain Res. 1139, 60-67 (2007).

21. Salès, $\mathrm{N}$. et al. Developmental expression of the cellular prion protein in elongating axons. Eur. J. Neurosci. 15, 1163-1177 (2002).

22. Lu, T. et al. REST and stress resistance in ageing and Alzheimer's disease. Nature 507, 448-454 (2014).

23. Song, Z. et al. REST alleviates neurotoxic prion peptide-induced synaptic abnormalities, neurofibrillary degeneration and neuronal death partially via LRP6-mediated Wnt-beta-catenin signaling. Oncotarget 7, 12035-12052 (2016).

24. Song, Z. et al. Downregulation of the repressor element 1-silencing transcription factor (REST) is associated with Akt-mTOR and Wnt- $\beta$-catenin signaling in prion diseases models. Front. Mol. Neurosci. 10, 128 (2017).

25. Song Z., Yang W., Zhou X., Yang L. \& Zhao D. Lithium alleviates neurotoxic prion peptide-induced synaptic damage and neuronal death partially by the upregulation of nuclear target REST and the restoration of Wnt signaling. Neuropharmacology 123, 332-348 (2017). 
26. Kaneko, N., Hwang, J., Gertner, M., Pontarelli, F. \& Zukin, R. S. Casein kinase 1 suppresses activation of REST in insulted hippocampal neurons and Halts ischemia-induced neuronal death. J. Neurosci. 34, 6030 (2014).

27. Li, S. et al. Soluble $A \beta$ oligomers inhibit long-term potentiation through a mechanism involving excessive activation of extrasynaptic NR2B-containing NMDA receptors. J. Neurosci. 31, 6627-6638 (2011).

28. Snyder, E. M. et al. Regulation of NMDA receptor trafficking by amyloid- $\beta$. Nat. Neurosci. 8, 1051-1058 (2005)

29. Kim, B. et al. The cellular prion protein $\left(\operatorname{Pr}^{C}\right)$ prevents apoptotic neuronal cell death and mitochondrial dysfunction induced by serum deprivation. Mol. Brain Res. 124, 40-50 (2004).

30. Gilland, E., Puka-Sundvall, M., Hillered, L. \& Hagberg, H. Mitochondrial function and energy metabolism after hypoxia-ischemia in the immature rat brain: involvement of NMDA-receptors. J. Cereb. Blood F. Met. 18, 297-304 (1998).

31. McKay, S., Bengtson, C. P., Bading, H., Wyllie, D. J. \& Hardingham, G. E. Recovery of NMDA receptor currents from MK-801 blockade is accelerated by $\mathrm{Mg}^{2+}$ and memantine under conditions of agonist exposure. Neuropharmacology 74, 119-125 (2013).

32. Ma, J. \& Lindquist, S. Wild-type PrP and a mutant associated with prion disease are subject to retrograde transport and proteasome degradation. Proc. Natl. Acad. Sci. USA 98, 14955-14960 (2001).

33. Yashiro, K. \& Philpot, B. D. Regulation of NMDA receptor subunit expression and its implications for LTD, LTP, and metaplasticity. Neuropharmacology $\mathbf{5 5}$ 1081-1094 (2008).

34. $\mathrm{Xu}, \mathrm{Z}$. et al. Metaplastic regulation of long-term potentiation/long-term depression threshold by activity-dependent changes of NR2A/NR2B ratio. J. Neurosci. 29, 8764-8773 (2009).

35. Talantova, $M$. et al. A $\beta$ induces astrocytic glutamate release, extrasynaptic NMDA receptor activation, and synaptic loss. Proc. Natl. Acad. Sci. USA 110 E2518-E2527 (2013).

36. Mony, L., Kew, J. N., Gunthorpe, M. J. \& Paoletti, P. Allosteric modulators of NR2B-containing NMDA receptors: molecular mechanisms and therapeutic potential. Br. J. Pharmacol. 157, 1301-1317 (2009).
37. Von Engelhardt, J. et al. Excitotoxicity in vitro by NR2A-and NR2B-containing NMDA receptors. Neuropharmacology 53, 10-17 (2007).

38. Liu, Y. et al. NMDA receptor subunits have differential roles in mediating excitotoxic neuronal death both in vitro and in vivo. J. Neurosci. 27, 2846-2857 (2007).

39. Terasaki, $Y$. et al. Activation of NR2A receptors induces ischemic tolerance through CREB signaling. J. Cereb. Blood F. Met. 30, 1441-1449 (2010).

40. Sgambato-Faure, V. \& Cenci, M. A. Glutamatergic mechanisms in the dyskinesias induced by pharmacological dopamine replacement and deep brain stimulation for the treatment of Parkinson's disease. Prog. Neurobiol. 96, 69-86 (2012).

41. Hallett, P. J. et al. Alterations of striatal NMDA receptor subunits associated with the development of dyskinesia in the MPTP-lesioned primate model of Parkinson's disease. Neuropharmacology 48, 503-516 (2005).

42. Gardoni, F. et al. Targeting NR2A-containing NMDA receptors reduces LDOPA-induced dyskinesias. Neurobiol. Aging 33, 2138-2144 (2012).

43. Rodenas-Ruano, A., Chavez, A. E., Cossio, M. J., Castillo, P. E. \& Zukin, R. S. RESTdependent epigenetic remodeling promotes the developmental switch in synaptic NMDA receptors. Nat. Neurosci. 15, 1382-1390 (2012).

44. Song, Z., Zhao, D. \& Yang, L. Metabolism of minor isoforms of prion proteins: cytosolic prion protein and transmembrane prion protein. Neural. Regen. Res. 8, 2868 (2013).

45. Weissmann, C. \& Flechsig, E. PrP knock-out and PrP transgenic mice in prion research. Br. Med. Bull. 66, 43-60 (2003).

46. Liu, J. et al. Prion protein participates in the protection of mice from lipopolysaccharide infection by regulating the inflammatory process. J. Mol. Neurosci. 55, 279-287 (2015).

47. Zhu T. et al. HDAC6 alleviates prion peptide-mediated neuronal death via modulating PI3K-Akt-mTOR pathway. Neurobiol. Aging 37, 91-102 (2015).

48. Song, Z. et al. Overexpression of BAT3 alleviates prion protein fragment PrP106-126-induced neuronal apoptosis. CNS. Neurosci. Ther. 20, 737-747 (2014). 